\title{
A Vegetation Similarity Index Driven by Distance-dependent Spatial Information
}

\author{
Pete Bettinger*
}

\begin{abstract}
A vegetation similarity index $(V S I)$, developed to describe the similarity of nearby vegetation conditions to each forest patch $(i)$, is presented as a new method for visualizing landscape heterogeneity. All forested patches within a certain distance $(M)$ of each patch $i$ are examined, and a value is developed to describe the similarity. These values are then weighted by an inverse distance method, and aggregated to produce a single value for each patch $i$. The distance $M$ examined can vary, and visual representations can be subsequently developed to assist biologists, planners, and policy makers in their understanding of vegetation similarity as viewed by various animal species. The VSI assesses the spatial configuration of vegetation conditions, and although it does not measure habitat loss due to particular natural or human-caused disturbances, it provides a new perspective on landscape vegetation similarity.

Keywords: landscape assessment, spatial analysis, fragmentation
\end{abstract}

\section{INTRODUCTION}

Forest fragmentation is one of the most hotly debated conservation issues facing land managers today because landscape disturbances are a noticeable consequence of landscape change (MCINTYRE, 1995), and the heterogeneity of landscapes has been shown to influence human perceptions (GEOGHEGAN et al., 1997). Fragmentation has been described as a process that spatially segregates those entities that would normally belong together in order to optimally function (CARSJENS and van LIER, 2002), and has been used as a process to describe the loss of certain habitat conditions (e.g., L $e t$ al., 2001). Forest fragmentation has also been described as a state of a landscape wherein elements of it have ecological characteristics that are very distinct from other elements, disrupting ecological connections between them and producing barriers to animal dispersion (FORMAN, 1995; JAEGER, 2000). Fragmentation of late-seral forests may result in smaller patch sizes than normally found in natural areas, an increased distance between patches containing similar forest structural conditions, and thus increased amounts of forest edge (D'EON, 2002), and isolation of original habitat (CARSJENS and van LIER,

\footnotetext{
* Warnell School of Forest Resources, University of Georgia, Athens, GA 30602, USA. pbettinger@ smokey.forestry.uga.edu
}

2002).

The main impacts of fragmentation are on wildlife species that are dependent on the size and configuration of interior habitat, however defined, thus fragmentation may result in local extinctions and losses of biodiversity (BAILLIE and Groombridge, 1996; Kouki et al., 2001). The effects of fragmentation, however, vary depending on the patterns and processes under investigation (RoBINSON et al., 1995; DONOvAN et al., 1997). For example, increased fragmentation across a landscape has been found to reduce the diversity of bird species, increase the number of edge species present, and reduce the number of species requiring interior forest habitat (MCINTYRE, 1995), although landscape heterogeneity has also been shown to be positively associated with bird abundance (McGARIGAL and McCOMB, 1995). The impacts of forest fragmentation have been postulated as complex and sitespecific (Lynch and Whigham, 1984), yet a landscape-scale perspective is important. For example, on a site-specific basis, forests fragmented by agriculture have been shown to result in a higher level of bird nest destruction than forests fragmented by logging, yet areas severely fragmented by logging and closer in proximity to human activity may show different results (BAYNE and HoBSON, 1997). However, a negative correlation has been found between the amount of edge at the landscape scale and the level of nest parasitization and predation (RoBINSON et al., 1995; DonOvan et al., 1997), thus generalist bird predators typical of fragmented landscapes seem to react more to landscape composition than to local 
fragment characteristics, as do certain medium-sized carnivores (OEHLER and Litvartis, 1996, Donavan et al., 1997). Few studies have examined the effects of fragmentation on managed forest landscapes, where older forests are surrounded by regenerating patches (ENOKSSON et al., 1995; McGarigal and McComb, 1995; HaGAN et al., 1996). Most fragmentation studies, in fact, have been undertaken to test the hypothesis that habitat loss is important to the existence and persistence of specific wildlife species (OPDAM 1991, WICKHAM et al., 1997), usually late-seral forest-dependent species. Further, Donovan et al. (1997) suggest that the first approximation to predicting the impact of edges on songbird reproductive success is to assess habitat characteristics at the landscape scale.

While the spatial patterning of landscape elements may be functionally linked to ecological processes occurring on the landscape (TURNER, 1989), human development processes also have an effect on landscape elements, and thus ecological processes. Forest edges generally have been described as sharp boundaries between contrasting environments (DoNOVAN et al., 1997), and edge effects can be considered either beneficial or detrimental, depending on the species or context under consideration (KREMSATER and BunNell, 1999).

Fragmentation need not always involve distinctly different habitats or sharp edges, since it can occur within a forest (ENOKSSON et al., 1995), via irregular gaps created by forest operations. These gaps usually have less long-term effect than more permanent changes in the landscape, such as gaps created by agriculture (DROLET et al., 1999), since forested landscapes fragmented by harvesting operations retain some forest structural conditions and tend to prevent invasion by generalist predators that can adapt to human-dominated landscapes (ANDRÉN, 1994). In forested landscapes fragmented by forestry operations late-seral forests might become separated by the introduction of younger forests of varying ages, and one might view the spatial and temporal location of late-seral forest as dynamic (MCGARIGAL and McComb, 1995).

Area-related edge effects in managed forests, such as the reduction in habitat quality due to changes in vegetation types, or competition by species able to better utilize a patchy landscape, require consideration of spatial and temporal changes in remnant patches of certain forest types and changes in edge effects (Schmiegelow et al., 1997). Thus simplified concepts, such as the area of certain habitat patches, are not adequate when considering dynamic landscape mosaics (HAILA et al., 1989).

At any given location in a landscape, forest patterns will be influenced by soil, topography, ownership, and management history, as well as urban pressure (WICKHAM et al., 2000). In terms of forest bird communities, fragmentation seems to result in more pest predation than in contiguous forested areas (RoBINSON et al., 1995), however the effects of fragmentation are mixed, since research shows that various measures of fragmentation send conflicting signals. For example, HOBSON and BAYNE (2000) found bird species richness to be higher in fragmented landscapes than in contiguous forests, yet this mainly occurred because the fragmented landscapes contained several bird species that are normally associated with edge habitats, while the contiguous landscape did not. FREEMARK and MERRIAM (1986) also indicate that larger forests are more important for increasing the number of forestinterior species, yet to maintain a diverse forest avifauna, they suggest that maximization of both forest size and habitat heterogeneity is important. The area of larger forest may, however, not be linearly related to the population size of some bird species, since forest remnants sufficiently large to include the size of a typical territory, may still be considered too small from a species' perspective (Drolet et al., 1999). SCHMIEGELow et al. (1997) point out that the size of older forests is important to the reproductive success of some bird species, and the availability of these patches over time and space should be considered in managed forests. Further, size differences in forested patches create forest habitat islands, and species composition in these islands is fairly predictable, whereas certain groups of species may be regularly absent from smaller patches (Ambuel and Temple, 1983). Drolet et al. (1999) suggest that travel patterns may also be disrupted by clearcuts, affecting the establishment or dispersal of some species across and landscape. Thus in dynamic landscapes, a simplified approach to measuring fragmentation may not be adequate.

The objective of this research is to develop a vegetation similarity index (VSI) which seeks to describe the similarity of the vegetative conditions across a landscape, yet leaves the interpretation of the ecological effects of vegetation similarity to biologists, planners, and policy makers. For example, the VSI indicates the level of similarity (or conversely, contrast) within certain distances (M) from each patch on the landscape. This measure may be useful in characterizing landscape structure (KücHLER, 1973). Forests can be considered homogenous in structure if forest conditions vary only a little across the landscape. However, boundaries between patches of vegetation may be either abrupt or gradual, and the level of heterogeneity may affect (positively or negatively) certain wildlife species. Heterogeneity, of course, depends on the scale at which it is measured (ForMAN and GODRON, 1986). Heterogeneity generally increases when the scale being viewed is broadened, and it reaches its highest level when viewed very closely. How wildlife perceive a landscape's vegetative condition is important for both active forest management and future policy analysis. For example, within a relatively homogeneous vegetative landscape, average air temperatures will vary little from one place to the next. If abrupt edges exist, indicating a more heterogeneous vegetative landscape, air temperature may be perceived as inhospitable to the movement of certain wildlife species with small home ranges. If predators of these species also concentrate within the different patches of vegetation, 
movement through or around these patches will be slow and hazardous (FORMAN and GODRON, 1986). Since wildlife use different landscape features for different purposes, understanding how the vegetation may be perceived at different scales can be important for forest management, research, and policy. Thus the interpretation of the ecological effects correlated with different VSI levels will vary from one wildlife species to the next, and be a function of the scale at which they perceive the environment. The VSI index is useful to biologists, planners, and policy makers in that it allows one to think spatially about landscape heterogeneity, since an index is computed for each unit of the landscape. Thus the VSI technique is unique in that it allows one to see where the areas of high (or low) vegetative similarity are on the landscape. Once mapped, the index can facilitate an evaluation of current or historical conditions as well as provide a basis for comparing future conditions projected by alternative landscape management plans.

The context of this research is somewhat different than that used in previous forest fragmentation research, in that large areas of homogenous landscapes may be more important for certain species of wildlife regardless of the structural condition. Similarly, heterogeneous landscapes are important for other species, and it is the delineation of the level of vegetation similarity across the landscape that is important. Thus the research focuses on vegetation similarity, not fragmentation, since it is similarity that is measured, not a deviation from a target forest structure (e.g., late-seral forest structure). While HERZoG et al. (2001) describe a set of metrics that may be used to describe landscape structure, and categorize them into metrics that relate to patch area, shape, diversity, and configuration, the metric described here combines the features of patch area, diversity, and configuration to provide a different view of the similarity of vegetation across a landscape.

\section{METHODS}

Measures of spatial structure generally include aspects related to the composition, configuration, and connectivity of resources. Several landscape metrics, in fact, can adequately quantify the major structural properties of a landscape (HERZOG et al., 2001), although landscape indices encountered in the literature have rarely undergone the scrutiny of assessing the correlation of the resulting measures with the success of foraging, reproduction, and dispersal of species of interest (Schumaker, 1996). Some of the most common landscape metrics related to the quantification of fragmentation or vegetative conditions described in the literature include assessments of the number of patches, patch area, core area, patch perimeter (edge), nearest-neighbor distance, contagion, fractal dimension, perimeter-area ratio, shape, and patch cohesion (SchUmaKeR, 1996). HARGis et al. (1998) examined the behavior of several commonly used metrics of forest fragmentation: edge density, contagion, mean nearest neighbor distance, mean proximity distance, perimeter-area fractal dimension, and mass fractal dimension, and note that none of these measures is able to differentiate between dispersed or aggregated spatial patterns. While the quantification of landscape structure is a prerequisite to studies of landscape function and change (Lr et al., 2001; McGarigal and McComb, 1995), there is no evidence that landscape metrics have generic application for the conservation of large sets of species, although they are useful in the quantification of landscape pattern from a human perspective (LINDENMAYER et al., 2002).

The application of fragmentation indices to landscapes should include a discussion about which landscape elements are being assessed, and should focus on the system property of interest (LI and Reynolds, 1995). The VSI developed here focuses only on forest stand age as a surrogate of vegetation similarity, an element which many ecologists, managers, and policy makers frequently use to describe the contiguity of a landscape. Other measures, such as tree species composition or forest structural condition (e.g., number of large trees or snags per unit area) could also be used as long as the differences between different conditions can be adequately quantified.

Perimeter, or edge, density is typically described as the total length of patch edge per unit area in a landscape (MCGARIGAL and MARKS, 1995), and it is sensitive to map resolution (HARGIS et al., 1998). Edge density is not sensitive to landscape pattern, however (HARGIs et al., 1998). Contagion describes the extent to which patches are aggregated. Contagion is calculated using the proportional representation of a certain cover type on a landscape, and the conditional probability that given a certain patch of land is cover type $i$, that a neighboring patch of land is cover type $j$ (McGARIGAL and MARKS, 1995; LI and REYNOLDS, 1993). Contagion is insensitive to landscape patterns in which patches are either widely dispersed or tightly clustered (HARGIS et al., 1998). Nearest-neighbor distance, or proximity, measures the isolation of a patch within a complex of patches, given a certain search radius (HARGIS et al., 1998), and is the ratio of the sum of the patch size to the nearest neighbor edge-to-edge distance (MCGARIGAL and MARKS, 1995). Mean nearest neighbor distance defines the average distance between patches, yet does not adequately describe the spatial distribution of patches across a landscape (HARGIS et al., 1998). Perimeter-area ratio and fractal dimension both provide information on the irregularity of patch edges on a landscape. These measures generally provide a patch-level statistic that makes comparing landscapes somewhat difficult if all patches exhibit similar irregularity. Patch cohesion is a relatively new concept that normalizes perimeter-area ratio by a shape index (SHUMAKER, 1996).

As one may have gathered, landscape metrics can be categorized as describing patch-scale characteristics or

\section{J. For. Plann. 9:73-83(2003)}


landscape-scale characteristics of resources. Patch-scale characteristics examine the conditions in the immediate vicinity of each patch. Landscape-scale characteristics look beyond the immediate vicinity of each patch, and include measures such as the distance to the nearest similar patch, the density of similar patches on a landscape, and other computations aggregated to a single measure to describe a large area (BAILEY et al., 2002).

\section{Measuring Vegetation Similarity}

The VSI proposed here attempts to measure the spatial configuration of classes of forest vegetation across a landscape. Stand age is used as the surrogate variable used to discriminate between vegetation classes. The VSI model is applied to a large landscape in western Oregon, composed mainly of coniferous tree species. Since forest structure generally changes as the age of coniferous stands increases, it seems intuitive that older forests generally contain taller trees than younger forests on similar sites with a similar composition of tree species. In fact, IsHII and McDowELL (2002) note that tree crown development in older forests is much different than crown development in younger forests. And, RoBbins (1980) suggests that canopy height and forest isolation are the most consistently important predictors of the abundance of some bird species. For example, neotropical migrants may be more abundant in forests where the trees are tall, although other factors such as plant diversity are also important (LYNCH and WHIGHAM, 1984).

There are a number of quantitative approaches for measuring the similarity between adjacent patches on a landscape. It is essential that landscape metrics provide unique contributions to the understanding of landscape structure or fragmentation. Correlation among metrics may be expected as they all tend to use similar basic parameters, such as patch size, patch shape, and interpatch distance (HARGIS et al., 1998). At a regional scale, WICKHAM et al. (1999) suggest graphing the proportion of forest area in the largest patch versus the proportion of area in anthropogenic cover to assess the degree of fragmentation. At this scale, however, distinctions between age groupings of forests are generally lost, and thus the discussion of edge and edge influences in specific species becomes fuzzy. Some landscape metrics can be used to calculate the proportion of similar (or dissimilar) area within a neighborhood around each patch. WICKHAM et al. (2000) illustrate the use of percolation thresholds, although these metrics do not necessarily measure the dispersion of similar or dissimilar patches, only the percent of area that is similar or dissimilar. At smaller landscape scales, other measures, such as the Shannon's diversity index (MCGARIGAL and MARKS, 1995) can be used:

$$
H^{\prime}=-\sum p_{i}\left(\ln p_{i}\right)
$$

Where:

$p_{i}=$ the proportional area of cover type $i$ on a landscape.

FreEMark and MERriam (1986) used a similar measure, the Shannon information function, to describe habitat heterogeneity in a study of bird use of temperate forest fragments. While these metrics can be used to evaluate fragmentation or landscape similarity, they require no spatial information other than knowing that a landscape condition is, or is not, present.

\section{Defining Edge}

MATLACK (1993) defines three edge types, recent, closed, and embedded. Recent edges are those where the side canopy of the residual forest has not closed, and diagonal beam radiation can enter. Closed edges are characterized by intact side canopies consisting of continuous vegetation from low shrubs to the tree crowns, thus little radiation enters the forest. Embedded edges are where young forests abut older forests, yet the tree heights are not exactly the same. In these cases, however, the crown canopies may be unbroken but there are differences in the underlying stand structures. All of these characterizations of edge can be related to age differences in forest stands. Edge, as defined here, represents simply a difference in the age of vegetation in adjacent patches (patches that share an edge).

\section{Inverse Distance Weighting of Differences in Stand Age}

Inverse distance weighting is based on the notion that differences in edge (stand age differences) nearby are more significant than differences more distant from a patch (WATSON and PHILIP, 1985). Inverse distance calculations for points across a landscape can be computed with the following process:

$$
\mathrm{G}(x, y)=\sum_{i=1}^{U} f\left(x_{i}, y_{i}\right) w_{i}
$$

with the weights $\left(w_{i}\right)$ equal to:

$$
w_{i}=d_{i}^{-p} / \sum_{j=1}^{U} d_{j}^{-p}
$$

Where:

$\mathrm{G}(x, y)=$ an estimated value for point $x, y$

$U=$ the set of points to be examined as neighbors of point $(x, y)$

$f\left(x_{i}, y_{i}\right)=$ the observed value at point $x_{i}, y_{i}$

$d_{i}=$ the distance from $(x, y)$ to $\left(x_{i}, y_{i}\right)$

$p=$ an arbitrary positive real number

The inverse distance weighting concept utilizes spatial data to estimate values on a landscape, thus the structure of the spatial data either inherently facilitates the computations (raster data), or the computations require ancillary adjacency 
Assume maximum buffer distance $=3,219 \mathrm{~m}$ (2 miles)

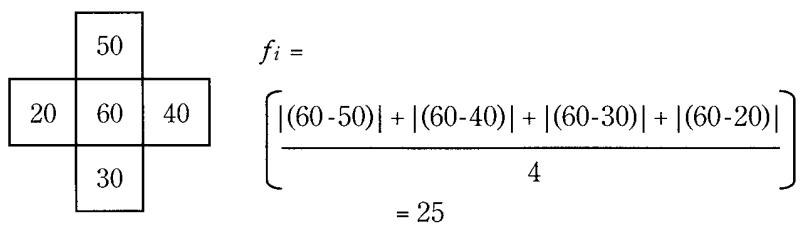

Fig. 1 Calculation of vegetation similarity (using stand age as a surrogate for forest structure) between a focal patch (age 60) and other patches that share an edge with the focal patch.

data (vector data). By changing the value of $p$, the distribution of weights can be changed from being highly biased in favor of the nearest data points $(p>1)$, to being nearly equal for all nearby data points $(p \leq 1)$.

Within the VSI computations, the average absolute difference in forest patch age $\left(f_{i}\right)$ between each patch $i$ and the set $\left(U_{i}\right)$ of adjacent patches to a patch $i$ is first evaluated (Fig. $1)$.

$$
f_{i}=\left[\frac{\sum_{j}^{U_{i}} \mid \text { Age }_{i}-\text { Age }_{j} \mid}{u}\right]
$$

Where:

$U_{i}=$ the set of adjacent patches to patch $i$

$u=$ the total number of adjacent patches to patch $i$

Thus if the ages of adjacent patches are all similar, the average age difference will be low. The average age difference will be high if the age of the adjacent patches is very diverse. There are some advantages and some drawbacks to this process. If the focal patch is mature forest, and the surrounding forest is all mature, yet one adjacent patch consists of young forest, the average age difference will be relatively low. If the focal patch is a young forest, and the surrounding forest is all mature, the average age difference will be high. While this may be important from the perspective of an organism currently in the focal patch, it may not adequately describe the larger condition of fragmentation across the landscape.

One alternative of this method may be to incorporate the length of the edges among adjacent patches, then weight the age differences by edge length as it relates to total edge length. Another alternative may be to use another metric other than age to describe the differences among patches. These considerations are left for future work, however. In order to weight each difference between patch $i$ and each neighboring
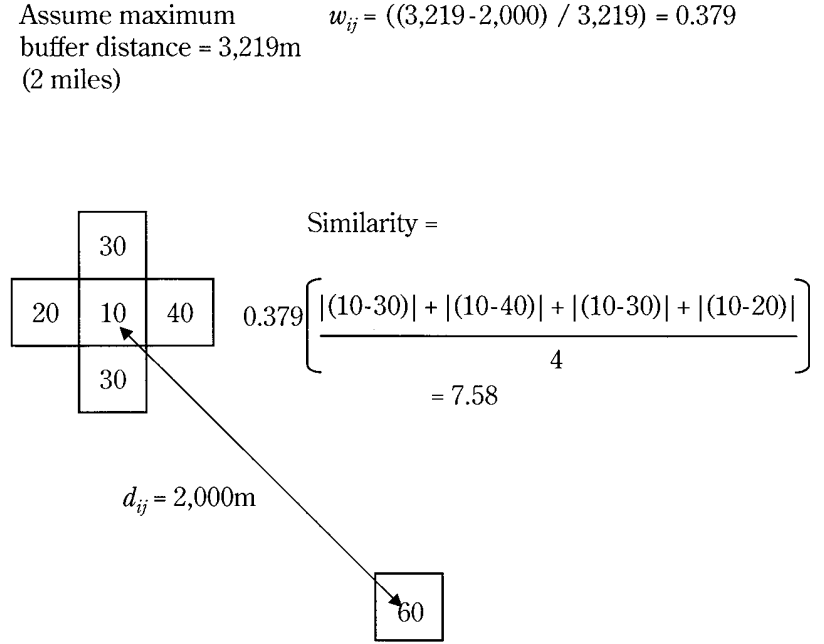

Fig. 2 Calculation of vegetation similarity (using stand age as a surrogate for forest structure) between a focal patch (age 60) and another patch that is within a certain distance $(3,219 \mathrm{~m})$ of the focal patch.

patch a distance $\left(d_{i j}\right)$ from patch $i$ to each patch $j$ in set $U_{i}$ is first determined:

$$
d_{i j}=\left[\left|x_{i}-x_{j}\right|^{2}+\left|y_{i}-y_{j}\right|^{2}\right]^{0.5}
$$

The weights applied to the vegetation similarity computations for each patch $j$ in the set $U_{i}$ are then assigned using the critical distance around each patch $(M)$ within which similarity is assessed:

$$
w_{i j}=\left[\left(M-d_{i j}\right) / M\right] \quad \forall j \in U_{i}
$$

The sum of the weights $\left(Z_{i}\right)$ from patch $i$ to all patches $j$ in the set $U_{i}$ is also calculated:

$$
Z_{i}=1+\sum_{j=1}^{U_{i}} w_{i j}
$$

Vegetation similarity (Fig. 2) is then evaluated for each patch $i$ :

$$
V S I_{i}=\left[\frac{f_{i}+\sum_{j=1}^{U_{i}}\left(f_{j} w_{i j}\right)}{Z_{i}}\right]
$$

All patches in $U_{i}$ are evaluated, including the vegetation similarity around unit $i$, where $d_{i j}$ is be equal to 1.0 , thus placing emphasis on the vegetation similarity around patch $i$. Patches in $U_{i}$ which are furthest from patch $i$ have less influence on $V S I_{i}$. Low $V S I$ scores indicate very similar vegetation exists nearby each patch $i$, and conversely, high VSI scores indicate dissimilar vegetation exists nearby each patch $i$. 
The VSI was applied to a large landscape in western Oregon (USA) (Fig. 3), where forest patches were defined by a process associated with the COASTAL LANDSCAPE ANALYSIS and Modeling Study (2002). The proportion of land area by vegetation age class shows a vast majority of land area is in

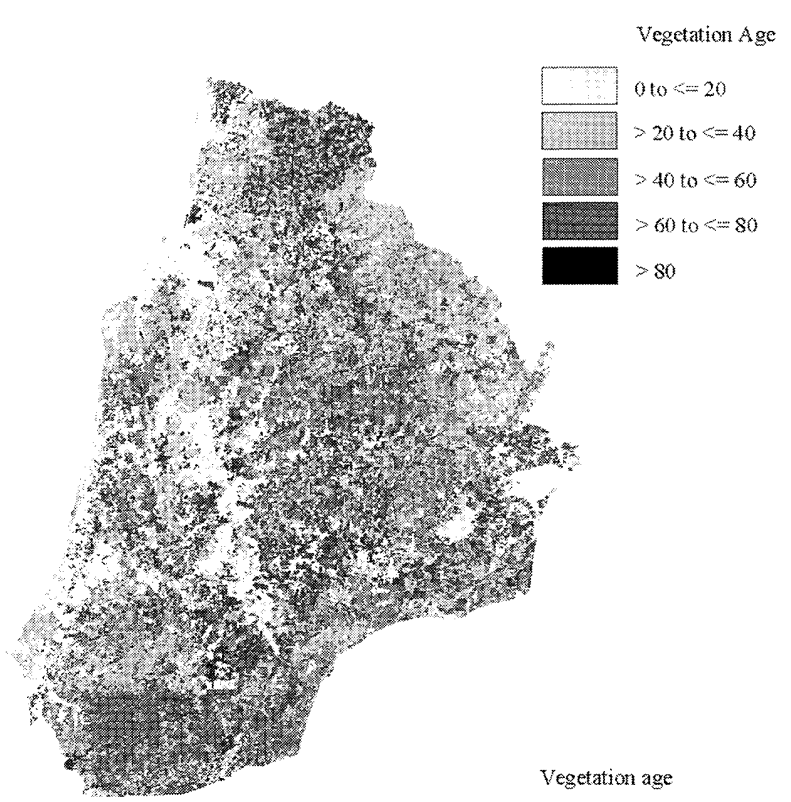

Fig. 3 Age class distribution of vegetation across a 589,512 ha land area on the coast of Oregon (USA).

Table. 1 Land area by vegetation age class for a large land area on the coast of Oregon (USA).

\begin{tabular}{lc}
\hline $\begin{array}{l}\text { Range of } \\
\text { age classes }\end{array}$ & Land area (ha) \\
\hline 0 to $\leq 20$ & 147,285 \\
$>20$ to $\leq 40$ & 208,889 \\
$>40$ to $\leq 60$ & 48,615 \\
$>60$ to $\leq 80$ & 60,444 \\
$>80$ & 124,279 \\
Total & 589,512 \\
\hline
\end{tabular}

vegetation age classes less than 40 years old (Table. 1 ), while a significant amount $(21.2 \%)$ is in the very old $(80+$ years) age class.

\section{RESULTS}

For purposes of illustration, VSI scores were assessed for each patch $i$ using five different maximum distance $(M)$ thresholds: $0 \mathrm{~m}, 805 \mathrm{~m}$ (0.5 miles), 1,609m (1 mile), 2,414m (1.5 miles), and $3,219 \mathrm{~m}$ ( 2 miles). The amount of land area within five VSI classes was then summarized: $0-20.00,20.01-40.00$, $40.01-60.00,60.01-80.00$, and $80.01+$. The total amount of land area that fell into five VSI classes shows a convergence from two sides of the scale (Table. 2). First, the amount of land area in the 0-20.00 VSI class seems to move upward into the 20.0140.00 VSI class as the maximum distance threshold $(M)$ increases. This indicates that similar vegetation classes may be initially grouped close together, yet when viewed from a broader perspective, the similarity of vegetation decreases (VSI increases). Second, the amount of land area in the 40.01+ $V S I$ classes generally decreases as $M$ increases, indicating that there is some heterogeneity of vegetation age classes present when viewed at a fine scale, yet when viewed from a broader landscape perspective, the similarity increases (VSI decreases). When viewed from the broadest perspective $(3,219 \mathrm{~m}$ buffer), the landscape vegetation is quite similar, with most of the land area $(84.6 \%)$ in the 20.01-40.00 VSI class.

Graphical descriptions of the VSI scores when a maximum distance threshold $M$ of $0 \mathrm{~m}$ was used (Fig. 4) are somewhat reflective of the initial age class distribution, and with a few exceptions reflect the heterogeneity of vegetation age classes inherent in the initial landscape. Areas on the northern portion of the landscape, for instance, have high levels of VSI due to the high degree of interspersion of older and younger forested areas. However, areas such as the most southern portion of the landscape, where a significant amount of older vegetation exist in the initial landscape, and interspersion of older and younger vegetation age classes is low, are portrayed as having low VSI scores, since many of the older forest patches are adjacent to one another. When $M$ is $0 \mathrm{~m}$, in fact, VSI is calculated using only the adjacent patches touching each patch $i$, thus presenting a very fine-scale picture of vegetation similarity.

Table. 2 Land area by VSI class for a large land area on the coast of Oregon (USA).

\begin{tabular}{lrrrrr}
\hline Range of & \multicolumn{5}{c}{ Maximum distance threshold $(M)$} \\
\cline { 2 - 6 } VSI classes & $0 \mathrm{~m}$ & $805 \mathrm{~m}$ & $1,609 \mathrm{~m}$ & $2,414 \mathrm{~m}$ & $3,219 \mathrm{~m}$ \\
\hline & \multicolumn{5}{c}{ Land area (ha) } \\
0 to $\leq 20$ & 244,960 & 138,725 & 87,390 & 59,149 & 43,189 \\
$>20$ to $\leq 40$ & 202,266 & 327,883 & 423,593 & 472,275 & 498,965 \\
$>40$ to $\leq 60$ & 96,899 & 116,671 & 77,529 & 58,078 & 47,358 \\
$>60$ to $\leq 80$ & 33,805 & 5,775 & 995 & 10 & 0 \\
$>80$ & 11,582 & 458 & 5 & 0 & 0 \\
\hline
\end{tabular}


When $M$ is increased to $805 \mathrm{~m}$ (Fig. 5), the fine-scale delineation of VSI classes begins to dissipate, and broader groupings of similar and dissimilar vegetation begin to appear.

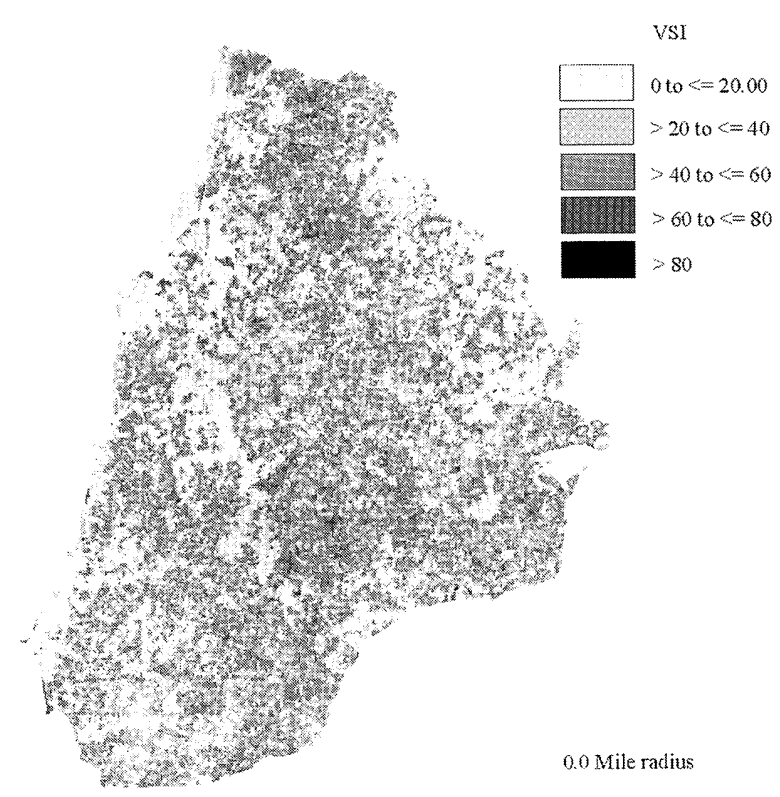

Fig. 4 VSI classes for all patches across a 589,512 ha landscape when the maximum distance threshold for calculating VSI is $0 \mathrm{~m}$.

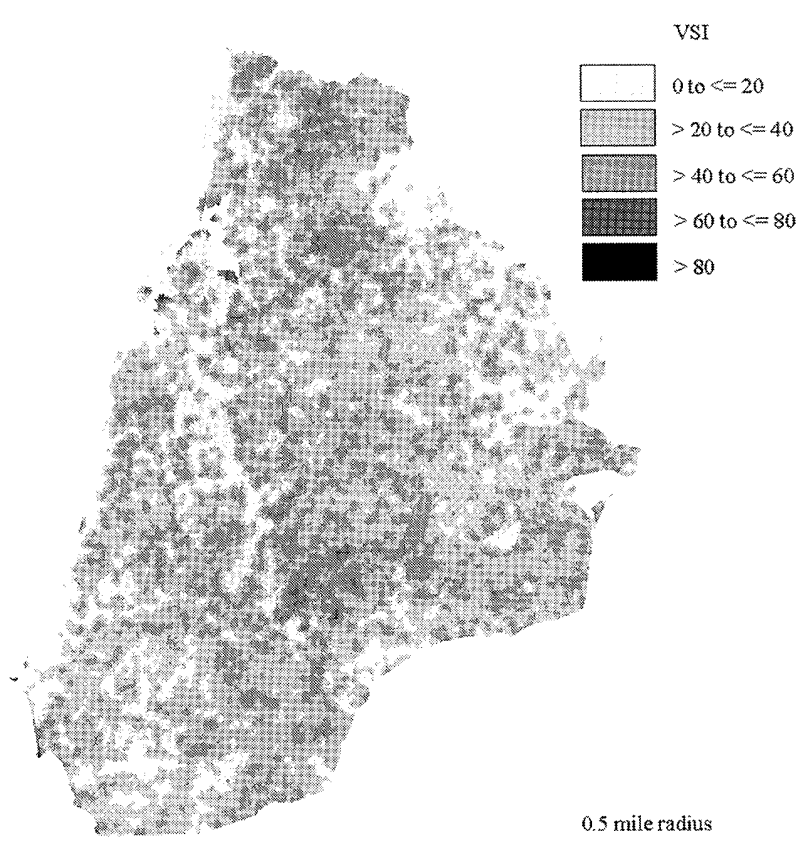

Fig. 5 VSI classes for all patches across a 589,512 ha landscape when the maximum distance threshold for calculating VSI is $805 \mathrm{~m}$.
As $M$ is increased to $1,609 \mathrm{~m}$ (Fig. 6), 2,414m (Fig. 7), and $3,219 \mathrm{~m}$ (Fig. 8), one can begin to view how differences in vegetation condition might be viewed at broader landscape

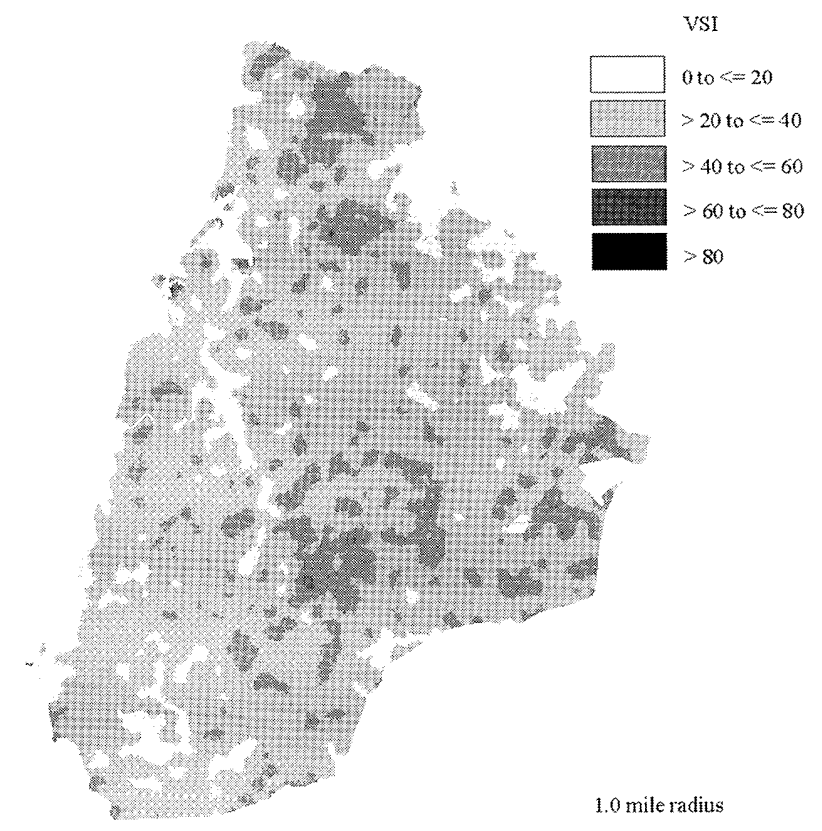

Fig. 6 VSI classes for all patches across a 589,512 ha landscape when the maximum distance threshold for calculating VSI is $1,609 \mathrm{~m}$.

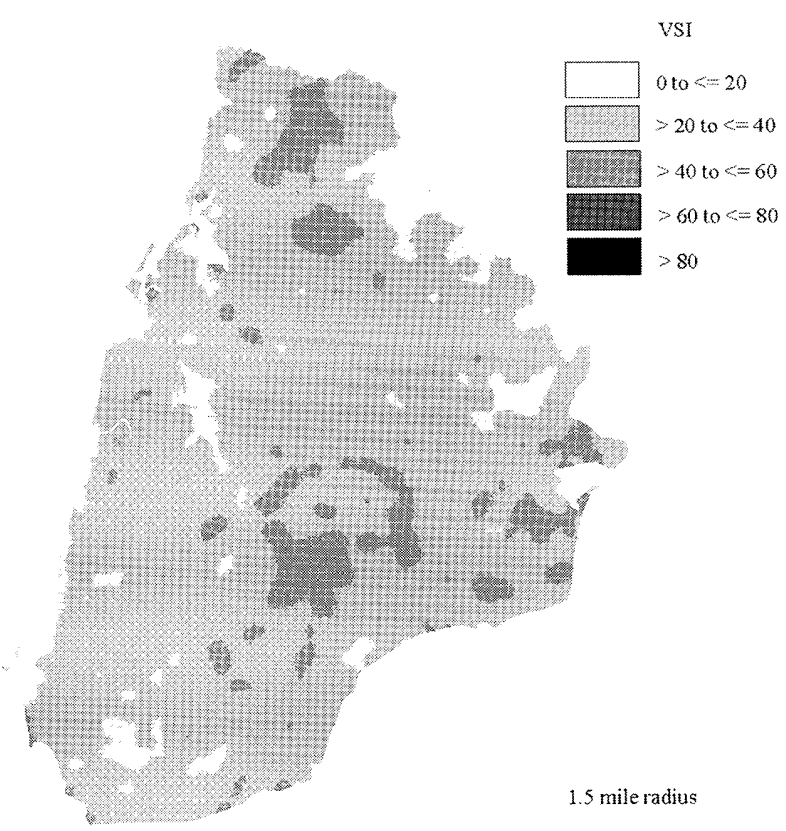

Fig. 7 VSI classes for all patches across a 589,512 ha landscape when the maximum distance threshold for calculating VSI is $2,414 \mathrm{~m}$. 


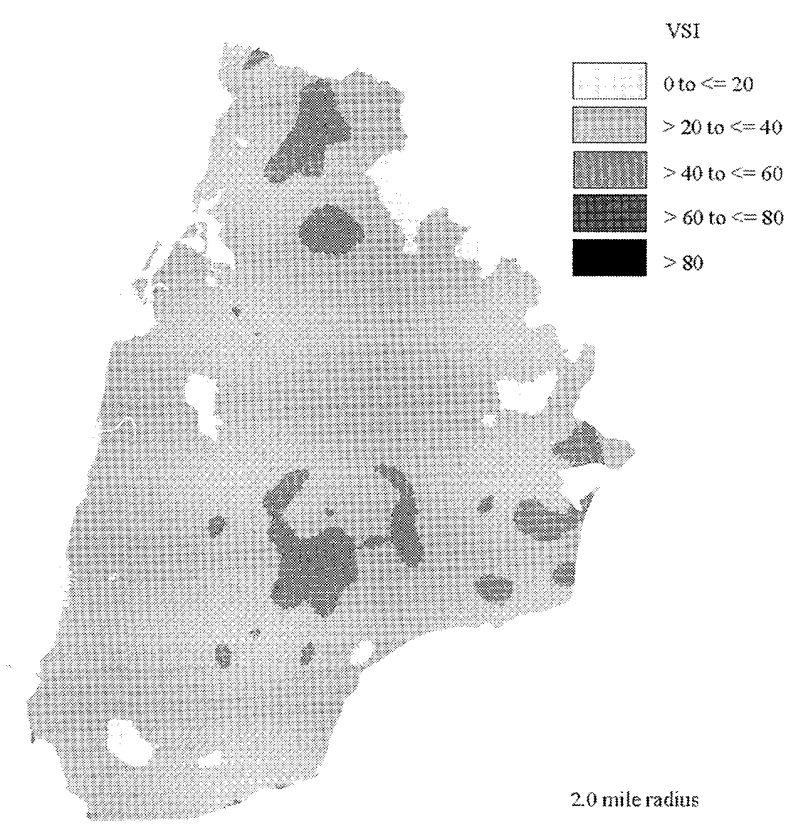

Fig. 8 VSI classes for all patches across a 589,512 ha landscape when the maximum distance threshold for calculating VSI is $3,219 \mathrm{~m}$.

scales. The areas of high interspersion of different vegetation classes thus become quite evident at these scales.

\section{DISCUSSION}

Landscape metrics probably do not have generic applicability for the conservation of large numbers of species, but may be useful where the aim of management is to quantify landscape patterns from a human perspective, or to measure the change that is occurring across a landscape (LINDENMAYER et al., 2002). The objective in the development of this spatial $V S I$ has been to evaluate the differences in vegetation condition across a landscape, with condition defined as the age of the vegetation in a patch. The technique described here may be complementary to others presented in the literature (e.g., patch size, shape, edge, nearest-neighbor, diversity, contagion, interspersion, patch cohesion). The dynamics of landscape change have not been evaluated, yet with a timeseries of historical or projected landscape conditions, one can analyze the differences in vegetation similarity with overlay functions contained within a geographic information system program.

Habitat configuration and subdivision undoubtedly play a role in regulating population abundance, distribution, and dynamics, but the magnitude of this may vary over space and time in relation to changes in regional habitat conditions (McGARIGAL and McComb, 1995). Almost every patch within a given forested landscape is habitat for some biotic species. If conservation strategies (e.g., THOMAS et al., 1990) suggest that amounts of certain habitat conditions must be retained in certain spatial configurations, then the VSI may allow the quantitative evaluation of how similar habitat conditions (as defined by forest age class) are within and among the current or projected conditions of a landscape.

The need to be cognizant of the scale at which landscape metrics are applied has been noted as important (CALE and HoBBs, 1994). For example, landscape metrics do not capture the structural attributes at a fine scale (the tree or smaller) that may be important for estimating the distribution or abundance of certain species. The VSI described here obviously ignores fine-scale differences in vegetation, such as patches of trees less than 10 ha that may be important nesting, roosting or foraging habitat for certain species of wildlife, for example, as these conditions are aggregated into larger patches. Spatial heterogeneity at a small scale is associated with higher species richness, because the differentiation of vegetation prevents exclusion by a single superior species (OlfF and RitchIE, 2002). Smaller levels of VSI may therefore shed light into where these areas might be located, given an assumption that age differences in forested areas imply habitat differences due to the presence of different structural conditions. The critical scale at which the positive effects of landscape heterogeneity switch to negative effects increases with the size and mobility of the species under consideration (O’NeILl et al., 1989; OlFF and RiTchie, 2002).

JAEGER (2000) discusses several desirable features of fragmentation indices: consistent behavior among the various stages of fragmentation (perforation, incision, dissection, dissipation, shrinkage, and attrition), intuitive interpretation, insensitivity to omission or addition of small residual areas, low data requirements, and mathematical simplicity. Although the VSI (which can be classed as a subset of fragmentation indices) described here does not adhere to all of these characteristics, it does have the following five features. First, the behavior is consistent with the various stages of fragmentation. Fragmentation is considered highest during the dissipation stage, where there is a thorough mixture of patches with distinctly different characteristics, and it is lowest in the perforation and attrition stages, since these are seen as being similarly fragmented (e.g., either mostly older forest, or mostly younger forest). Thus the view from which fragmentation is made depends on the state the landscape currently occupies. For example, a landscape with mostly younger forest may not be ecologically desirable for some species, yet it is for other species, thus fragmentation of a younger forest landscape (allowing urban areas to encroach, or setting aside certain patches to grow into older forest conditions) may also occur. Second, the intuitive appeal of the VSI model described here is evident: the differences among adjacent forest stands is measured, and the spatial heterogeneity of the landscape within a certain distance of each patch is taken into account. Third, the addition of small 
areas or other landscape elements have little effect on the calculations. Fourth, the data requirements are moderate: a geographic information system database of the landscape is required, some knowledge of the spatial relationship of landscape elements is required, as is some knowledge of the condition of each patch. Fifth, and finally, the index described here is not mathematically simple. JAEGER (2000) emphasizes that only simple measures will be used in practice, yet FRAGSTATS (MCGARIGAL and MARKS, 1995) is widely used, and contains some very complex measures, such as proximity, contagion and interspersion and juxtaposition indices.

The VSI may also provide a different perspective on the effects of landscape change. Not from the perspective traditionally taken by landscape ecologist, that fragmentation of a landscape is some change from an older forested state, but rather the VSI illustrates how different a landscape is perceived from the perspective of various species that have a distinct spatial home range. It is similar to a diversity index, yet calculated for each patch on the landscape, and what is meaningful are maps describing concentrations of very dissimilar vegetation. Since ecologists are interested in the spatial distribution of patches (HARGIS et al., 1998), and policy makers are increasingly becoming interested in spatial representations of proposed forest policies, a landscape metric that quantifies spatial arrangement seems to be increasingly important.

A number of issues related to the application of the VSI remain to be examined, including the insight a measure such as VSI can provide toward the potential for habitat corridors across certain regions of a landscape. It may also facilitate an examination of the effects that gaps in preferred habitat within managed forests have on barriers to species' movement across a landscape.

\section{CONCLUSIONS}

This research represents an advance in the area of landscape measures of vegetation similarity, a subset of fragmentation indices, and one of four areas of study encouraged by the International Studygroup on Multiple Use of Land (CARSJENS and van LIER, 2002). Landscape measures of fragmentation have also been noted as one of the key criterion (1.1e) of the Montreal Process (CANADIAN ForEST SERvice, 2000) for guiding the conservation of species biodiversity within managed forests, and this research presents a tool that characterizes the spatial configuration of vegetation across a landscape, as opposed to the composition or connectivity of habitat. It is assumed here that patch vegetation age is a surrogate for forest structural condition, and is in direct correlation with forest tree height across a landscape, although certainly differences in site index from stand to stand cloud the issue. Any other type of forest structural condition (e.g., number of large trees or snags per unit area) could be used to describe the differences in vegetation, however.
Management units (patches) represented by vector polygons, were used to conduct the analysis, and the distance weighting procedure was based on the centroid of each. Groups of residual leave trees (legacy trees) within management units are therefore ignored, since a patch was defined by a single vegetation age. The objective was to measure vegetation similarity and to provide biologists, foresters, and decisionmakers with a metric that will allow them to make inferences about the effect of different management policies on the relative fragmentation of a forested landscape, as defined by the spatial arrangement of different types of forest structure.

Estimates of vegetation similarity using the spatially explicit model are sensitive to the assumption regarding the distance around a focal patch to which similarity is evaluated. Other patterns represented by rates of forest conversion to agriculture, urbanization pressures, and changes in management behavior of forest management organizations also affect fragmentation and vegetation similarity measures, although these hypotheses were not tested. Although the VSI does not measure the habitat loss due to particular disturbances (natural or human-caused), it provides insight into the similarity of vegetation classes across a broad landscape. The logical next steps in this research would be to examine the correlation and synergy of this technique with other established techniques, and to attempt to correlate species behavior (foraging, reproduction, dispersal), presence, or abundance to VSI levels to determine the landscape requirements for various species, and how sensitive species characteristics are to various VSI levels.

\section{LITERATURE CITED}

Ambuel, B. and Temple, S.A., (1983): Area-dependent changes in the bird communities and vegetation of southern Wisconsin forests. Ecology 64: 1057-1068

ANDrÉn, H., (1994): Effects of habitat fragmentation on birds and mammals in landscapes with different proportions of suitable habitat: a review. Oikos 71: 355-366

Bailey, S.-A., Haines-Young, R.H. and Watkuns, C., (2002): Species presence in fragmented landscapes: modelling of species requirements at the national level. Biological Conservation 108: 307-316

Baillie, J. and Groombridge, B. (compilers and editors), (1996): 1996 IUCN Red List of Threatened Animals. IUCN, Gland, Switzerland and Cambridge, UK

Bayne, E.M. and Hobson, K.A., (1997): Comparing the effects of landscape fragmentation by forestry and agriculture on predation of artificial nests. Conservation Biology 11: 1418-1429

Coastal Landscape Analysis and Modeling Study (CLAMS), (2002): CLAMS home page. http://www.fsl.orst.edu/clams/ (accessed 02/07/03)

CALE, P.G. and HoBBS, R.J., (1994): Landscape heterogeneity indices: problems of scale and applicability, with particular reference to animal habitat description. Pacific Conservation Biology 1: 183-193

CANAdian Forest SERvice., (2000): The Montreal Process: Year 2000 
progress report. Canadian Forest Service, Ottawa, Canada

Carsiens, G.J. and van Lier, H.N., (2002): Fragmentation and landuse planning - an introduction. Landscape and Urban Planning 58: $79-82$

D'EON, R.G., (2002): Forest fragmentation and forest management: A plea for empirical data. The Forestry Chronicle 78: 686-689

Donovan, T.M., Jones, P.W., Annand, E.M. and Thompson III, F.R., (1997): Variation in local-scale edge effects: mechanisms and landscape context. Ecology 78: 2064-2075

Drolet, B., Desrochers, A. and Fortin, M.J., (1999): Effects of landscape structure on nesting songbird distribution in a harvested boreal forest. Condor 101: 699-704

Enoksson, B., Angelstam, P. and Larsson, K., (1995): Deciduous forest and resident birds: the problem of fragmentation within a coniferous landscape. Landscape Ecology 10: 267-275

Forman, R.T.T., (1995): Land mosaics. The ecology of landscapes and regions. Cambridge University Press, Cambridge. 632 p.

Forman, R.T.T. and Godron, M., (1986): Landscape Ecology. John Wiley \& Sons, Inc., New York. 619 p.

FreEMARK, K.E. and MERriam, H.G., (1986): Importance of area and habitat heterogeneity to bird assemblages in temperate forest fragments. Biological Conservation 36: 115-141

Geoghegan, J., Wainger, L.A. and Bockstael, N.E., (1997): Spatial landscape indices in a hedonic framework: An ecological economics analysis using GIS. Ecological Economics 23: 251-264

HaGAN, J.M., Vander Haegen, W.M. and McKinley, P.S., (1996): The early development of forest fragmentation effects on birds. Conservation Biology 10: 188-202

Haila, Y., Hanski, I.K. and RaIVIO, S., (1989): Methodology for studying the minimum habitat requirements of forest birds. Annales Zoologici Fennici 26: 173-180

Hargis, C.D., Bissonette, J.A. and David, J.L., (1998): The behavior of landscape metrics commonly used in the study of habitat fragmentation. Landscape Ecology 13: 167-186

Herzog, F., Lausch, A., Müller, E., Thulke, H.-H., Steinhardr, U. and LEHMANN, S., (2001): Landscape metrics for assessment of landscape destruction and rehabilitation. Environmental Management 27: 91-107

Hobson, K.A. and BAYNe, E., (2000): Effects of forest fragmentation by agriculture on avian communities in the southern boreal mixedwoods of western Canada. Wilson Bulletin 112: 373-387

IshiI, H. and McDowell, N., (2002): Age-related development of crown structure in coastal Douglas-fir trees. Forest Ecology and Management 169: 257-270

JAEGER, J.A.G., (2000): Landscape division, splitting index, and effective mesh size: new measures of landscape fragmentation. Landscape Ecology 15: 115-130

Kouki, J., Löfman, S., Martikainen, P., Rouvinen, S. and Uotila, A., (2001): Forest fragmentation in Fennoscandia: linking habitat requirements of wood-associated threatened species to landscape and habitat changes. Scandinavian Journal of Forest Research (Supplement) 3: 27-37

Kremsater, L. and Bunnell, F.L., (1999): Edge effects: theory, evidence and implications to management of western North American forests (In Rochelle, J.A., L.A. Lehmann and J. Wisniewski, (eds.) Forest fragmentation: wildlife and management implications). Koninklijke Brill, Leiden, Netherlands. pp. 117-
153

KüCHLER, A.W., (1973): Problems in classifying and mapping vegetation for ecological regionalization. Ecology 54: 512-523

LI, H. and Reynolds, J.F., (1993): A new contagion index to quantify spatial patterns of landscapes. Landscape Ecology 8: 155-162

Li, H. and ReynolDS, J.F., (1995): On definition and quantification of heterogeneity. Oikos 73: 280-284

Li, X., Ling, L., Cheng, G. and XiaO, H., (2001): Quantifying landscape structure of the Heihe River Basin, north-west China using FRAGSTATS. Journal of Arid Environments 48: 521-535

Lindenmayer, D.B., Cunningham, R.B., Donnelly, C.F. and Lesslie, R., (2002): On the use of landscape surrogates as ecological indicators in fragmented forests. Forest Ecology and Management 159: 203-216

LYNCH, J.F. and WHIGHAM, D.F., (1984): Effects of forest fragmentation on breeding bird communities in Maryland, USA. Biological Conservation 28: 287-324

Magurran, A., (1988): Ecological diversity and its measurements. Princeton University Press, Princeton, N.J

MATLACK, G.R., (1993): Microenvironment variation within and among forest edge sites in the eastern United States. Biological Conservation 66: 185-194

McGARIGAL, K. and MARKs, B.J., (1995): FRAGSTATS: Spatial pattern analysis program for quantifying landscape structure. USDA Forest Service, Pacific Northwest Research Station, Portland, OR. General Technical Report PNW-GTR-351. $122 \mathrm{p}$

McGarigal, K. and McComb, W.C., (1995): Relationships between landscape structure and breeding birds in the Oregon Coast Range. Ecological Monographs 65: 235-260

MCINTYRE, N.E., (1995): Effects of forest patch size on avian diversity. Landscape Ecology 10: 85-99

OEHLER, J.D. and Litvaitis, J.A., (1996): The role of spatial scale in understanding responses of medium-sized carnivores to forest fragmentation. Canadian Journal of Zoology 74: 2070-2079

OlfF, H. and RitchiE, M.E., (2002): Fragmented nature: consequences for biodiversity. Landscape and Urban Planning 58: 83-92

O’Neill, R.V., Milne, B.T., Turner, M.G. and Gardner, R.H., (1989): Resource utilization scales and landscape patter. Landscape Ecology 2: 63-69

OpDAm, P., (1991): metapopulation theory and habitat fragmentation: A review of holarchic breeding bird studies. Landscape Ecology 5: 93-106

RoBbins, C.S., (1980): Effect of forest fragmentation on breeding bird populations in the Piedmont of the mid-Atlantic region. Atlantic Naturalist 33: $31-36$

Robinson, S.K., Thompson III, F.R., Donovan, T.M., WhiteheaD, D.R. and FAABORG, J., (1995): Regional forest fragmentation and the nesting success of migratory birds. Science 267: 1987-1990

Schmiegelow, F.K.A., Machtans, C.S. and Hannon, S.J., (1997): Are boreal birds resilient to forest fragmentation? An experimental study of short-term community responses. Ecology 78: 1914-1932 SCHUMAKER, N.H., (1996): Using landscape indices to predict habitat connectivity. Ecology 77: 1210-1225

Thomas, J.W., Forsman, E.D., Lint, J.B., Meslow, E.C., Noon, B.R. and VERNER, J., (1990): A conservation strategy for the northern spotted owl: report to the interagency scientific committee to address the conservation of the northern spotted owl. U.S. 
Government Printing Office, Washington, D.C.

Turner, M.G., (1989): Landscape ecology: the effect of pattern on process. Annual Review of Ecology and Systematics 20: 171-197

Watson, D.F. and Philir, G.M., (1985): A refinement of inverse distance weighted interpolation. Geo-Processing 2: 315-327

Wickham, J.D., Jones, K.B., Rirrers, K.H., Wade, T.G. and O'NeILL, R.V., (1999): Transitions in forest fragmentation: implications for restoration at regional scales. Landscape Ecology 14: 137-145
WickHAM, J.D., O'Neill, R.V. and Jones, K.B., (2000): Forest fragmentation as an economic indicator. Landscape Ecology 15: $171-179$

WickHAM, J.D., Wu, J. and BradFord, D.F., (1997): A conceptual framework for selecting and analyzing stressor data to study species richness at large spatial scales. Environmental Management 21: 247-257

(Received 1 March 2003) (Accepted 15 August 2003)

J. For. Plann. 9:73-83(2003) 